\title{
1 Forensic application of a rapid one-step tetramethylbenzidine-based test \\ 2 for the presumptive trace detection of bloodstains at the crime scene and 3 in the laboratory
}

4 Elisabetta De Vittori 1,4, Filippo Barni ${ }^{2 *}$, Simon W. Lewis ${ }^{3}$, Giovanni Antonini ${ }^{1}$, Cesare Rapone ${ }^{2}$, and Andrea Berti ${ }^{2}$

${ }^{1}$ Roma Tre University - Sciences Department, Viale Guglielmo Marconi, 446, 00146, Roma, Italy.

${ }^{2}$ Carabinieri Scientific Investigations Department of Rome - Forensic Biology Unit, Viale di Tor di Quinto 119, 00191, Rome, Italy.

${ }^{3}$ Curtin University - Nanochemistry Research Institute and Department of Chemistry, GPO Box U1987 Perth, Western Australia 6845, Australia.

${ }^{4}$ Legal Genetics Forensic Consulting, Via Po, 102 - 00198, Rome, Italy.

*Corresponding Author; e-mail address: filippo.barni@carabinieri.it.

Abstract

Bloodstains are a widespread kind of biological evidences at the crime scene and one of the most used reagents for the presumptive identification of blood for forensic purposes is tetramethyl-benzidine. We have introduced and validated the tetramethylbenzidine-based Combur $\stackrel{3}{=}$ Test $^{\circledR}$ E (Roche Diagnostics Corporation, Basel, Switzerland), a colorimetric catalytic test based upon the detection of the peroxidase-like activity of the hemoglobin, due to its high sensitivity, easiness of use and capability to maintain the complete structural and morphological integrity of the bloodstain. Analytical performances related to a forensic use of the test and the suitable applicability to the presumptive detection of bloodstains when extremely diluted, aged, mixed with several substances and deposed over a plethora of substrates was reliably proved. In addition, possible positive interferences of the test chemicals on the subsequent Short Tandem Repeats (STRs) DNA typing analyses, especially in Low-Template DNA (LT DNA) conditions, was evaluated.

While the Combur $\underline{3}$ Test $^{\circledR}$ E showed the same chemical interference drawbacks as other presumptive tests for blood, we demonstrated that its format and our suggested protocol of use make it appropriate for the forensic presumptive detection of blood, better performing and much easier to use than other analogous presumptive tests and usually compatible with the following STRs DNA typing analyses. 


\section{Keywords}

bloodstains, presumptive test, 3,3' $3^{\prime}, 5^{\prime}$-tetramethylbenzidine, STRs DNA typing.

\section{Introduction}

Bloodstains are commonly found at the scenes of crimes involving violence, and they are potentially highly informative since they may provide investigators with information concerning the donor's DNA profile and also the blood deposition dynamic at the crime scene through bloodstain pattern analysis (BPA). Typically, chemical presumptive tests for the presence of blood are used in locating spots and stains that might not be obvious to the naked eye.

Presumptive tests for blood are mostly catalytic tests [1] that rely on the catalytic effect of hem and its derivatives on the breakdown of hydrogen peroxide. These typically involve the oxidation of another substance in the reaction mixture that leads to a colour change. They are very sensitive, robust, reproducible, and require very little sample to make a presumptive blood determination, they often lack in specificity $[2,3,4]$. Although they are not human-specific they provide an indicative result when other more confirmatory tests could not be applicable, such as when blood evidence is present in trace amounts and/or is highly compromised due to degradation.

One of the most routinely used category of presumptive tests for blood screening is that based on the 3,3',5,5'-tetramethylbenzidine (TMB) colorimetric change in the presence of blood and of an oxidant (usually a peroxide) due to the peroxidase-like activity of the oxidized hem prosthetic group, named hematin (containing $\mathrm{Fe}^{3+}$ ), in the hemoglobin moiety found within red blood cells $[3,5,6]$.

The Combur $\underline{3}$ Test ${ }^{\circledR}$ E (Roche Diagnostics Corporation, Basel, Switzerland) is a routinely used diagnostic test for semiquantitative determination of hematuria and of other parameters [7]. The plastic strip possesses a reagent-treated filtered paper tab at one end that contains TMB, dimetyldihydroperoxiesane, buffering materials and non-reactants which turns from yellow to intense dark blue-green when blood come into contact with the reactive tab (Fig. 1). 


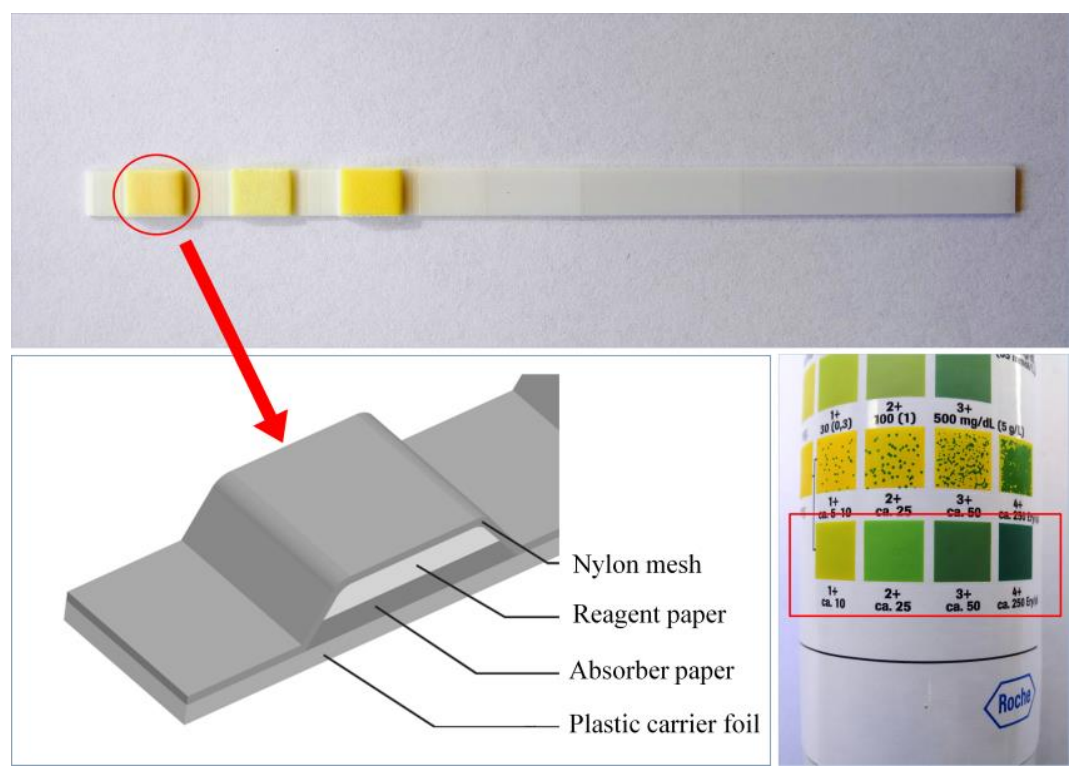

Fig. 1. The Combur $\underline{3}$ Test ${ }^{\circledR}$ E strip with indicated the reactive tab containing TMB used to presumptively detect blood and the architecture of the tab; also the colors scale (from yellow-pale greenish to intense blue-green) printed on the vial label to interpret results of the test is reported.

In this paper we report an evaluation of the Combur $\underline{3}$ Test ${ }^{\circledR} \mathrm{E}$ for forensic bloodstains detection, based on the ISO (International Organization for Standardization) standards [8] for the best laboratory practice and on the main guide-lines concerning methods validation drafted by Eurachem [9], IUPAC (International Union of Pure and Applied Chemistry) [10,11], and ICH (International Conference on Harmonisation of Technical Requirements for Registration of Pharmaceuticals for Human Use) [12]. In addition we compared the analytical performances of the Combur $\underline{3}^{-}$Test $^{\circledR} \mathrm{E}$ with respect to other presumptive tests for blood detection (the Hemastix ${ }^{\circledR}$ test, the phenolphthalein test and the leucomalachite-green test). The compatibility of Combur $\underline{3}$ Test ${ }^{\circledR} E$ with subsequent DNA typing procedures using multiplex-PCR kits, especially in LT DNA contexts, was also investigated.

\section{Materials and Methods}

\subsection{The Combur $\underline{3}$ Test $^{\circledR} E$}

For the presumptive detection of bloodstains the reactive tab on the Combur ${ }^{3}$ Test ${ }^{\circledR}$ E test strip was briefly and slightly moistened with distilled water and, following, it was directly put into contact with the questioned stain for not more than 5 seconds. The detection of typical color change to intense bluegreen usually within 20-30 seconds suggests the presumptive presence of blood. The read of the test result after about 30-40 seconds does not have any affordable significance and may only be misleading because of some spontaneous TMB oxidation due to environmental oxidizing compounds with a low standard reduction potential $[1,7,13,14]$. Several metrological analytical parameters were considered for 
the forensic performances evaluation of the Combur ${ }^{3}$ Test ${ }^{\circledR}$ E according mainly with IUPAC guidelines $[10,11]$. The evaluated parameters (limit of detection, specificity, interference, robustness, precision, accuracy) were slightly revised and fitted to the specific context of a forensic use as described in detail in supplementary material (Appendix A).

\subsection{Comparison to other tests used for the forensic individualization of blood}

The Combur ${ }^{3}$ Test $^{\circledR} \mathrm{E}$ was evaluated for detection limit and accuracy, and ease of use against commonly used presumptive tests for blood individualization: the phenolphthalein-based test Phenolphthalein Dischaps ${ }^{\mathrm{TM}}$ (Sirchie ${ }^{\circledR}$ Fingerprint Laboratories, Youngsville, NC, USA), the

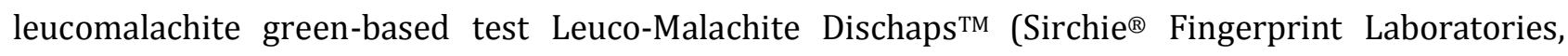
Youngsville, NC, USA), and another tetramethylbenzidine-based test, the Hemastix ${ }^{\circledR}$ test (Siemens Healthcare Diagnostics Inc., Deerfield, IL, USA) [15]. The presumptive presence of blood causes the appearance, within few seconds (usually within 30-40 seconds), on the absorbent paper of a pink color in the case of phenolphthalein test or of dark green color in the case of leucomalachite green test and a blue-green color on the reactive zone on the strip of the Hemastix ${ }^{\circledR}$ test (located on the top of the strip). Aliquots of $10 \mu \mathrm{l}$ of human blood (blood samples from individuals 1, 2, 3), undiluted and diluted according to dilution factors $10^{-1}, 10^{-2}, 10^{-3}, 10^{-4}, 10^{-5}, 10^{-6}$, were deposed on glass. Each bloodstain was tested with the Combur $\underline{3}$ Test ${ }^{\circledR} \mathrm{E}$ and with the three aforementioned tests.

In order to assess the accuracy of Combur $\underline{3}$ Test ${ }^{\circledR} \mathrm{E}$, the bloodstains diluted to $10^{-1}$ were also tested against a confirmative immunochromatographic test, the Seratec ${ }^{\circledR}$ HemDirect (Seratec ${ }^{\circledR}$ GmbH, Göttingen, Germany), commonly used in forensic biology as confirmative test for the identification of human blood. The test was accomplished on $10 \mu \mathrm{l}$ of fresh blood (sample 5) deposited on absorbent paper and let dry at room temperature; about $3 \mathrm{~mm}^{2}$ of each bloodstain were directly soaked in extraction buffer provided with the test (Tris-HCl pH 7.5) for 5 minutes and $150 \mu$ of each extract were loaded on the immunochromatographic test. Test results, according to the user's manual instructions, were read after 10 minutes. All the analyses were carried out in triplicate for each test.

\subsection{Human blood samples}

To evaluate the Combur ${ }^{3}$ Test ${ }^{\circledR}$ E analytical performance five fresh samples of human blood (numbered from 1 to 5 ) were taken by healthy volunteers by venipuncture, deposed in VACUETTE ${ }^{\circledR}$ tubes (Greiner Bio-One GmbH, Kremsmünster, Austria) containing K3 EDTA (1.8 mg/ml) and kept at $4^{\circ} \mathrm{C}$ until use. From these blood samples several bloodstains were prepared by spotting $10 \mu \mathrm{l}$ of human blood, both diluted in aqueous sodium chloride $(0.9 \% \mathrm{w} / \mathrm{v})$ and undiluted, on different substrates and letting them completely dry. Diluted blood samples factors ranged from $10^{-1}$ to $10^{-7}$ in order to resemble washed blood conditions commonly found at crime scene (further details are reported in 
Table A1). Both diluted and undiluted blood samples were deposited on different types of surfaces with a different degree of absorption of the blood: paper (high absorption); plywood (partial absorption); plasterboard (partial absorption); sheet metal painted (almost zero absorption); glass (no absorption). Unless differently indicated below, glass was used as an ideal surface to evaluate the test performances. Each bloodstain sample was analyzed with the Combur $\underline{3}$ Test $^{\circledR}{ }^{\circledR}$ at different times after deposition.

To verify whether the performance of Combur $\underline{3}$ Test ${ }^{\circledR}$ E was affected by the state of degradation of the human bloodstains due to time since deposition traces of blood dried on absorbent material from different real caseworks (the oldest from 1975, the latest from 2008) stored at room temperature until use were analyzed. The reactive zone of the strip of the Combur ${ }^{3}$ Test ${ }^{\circledR}$ E was put into contact with human bloodstains deposed on paper for samples from 1999, 2003, 2006, 2007, 2008 and on cloth for samples from 1975 and 2006 (Fig. A1).

\subsection{Non-human blood samples}

In order to evaluate the species-specificity of the Combur ${ }^{3}$ Test ${ }^{\circledR}$ blood from several animals was tested. Blood samples from the 14 different animal species reported below were provided by the experimental zooprophylactic Institute of Lazio and Tuscany regions: donkey (Equus asinus); dog (Canis familiaris); goat (Capra hircus); roe deer (Capreolus capreolus); horse (Equus caballus); wild boar (Sus scrofa); fallow deer (Dama dama); rooster (Gallus gallus); cat (Felis catus); wolf (Canis lupus); sheep (Ovis aries); domestic pigeon (Columba livia); pig (Sus scrofa); cow (Bos taurus). From each blood sample $10 \mu \mathrm{l}$ were deposed on an inert surface (glass) and allowed to dry prior to testing.

\subsection{Body fluid samples}

To evaluate the biological fluid-specificity of Combur ${ }^{3}$ Test ${ }^{\circledR}$ E human saliva, urine, semen, feces $(10 \mathrm{~g})$ taken from healthy volunteers and put into $2 \mathrm{~mL}$ tubes and bird feces taken were tested. Aliquots of 10 $\mu \mathrm{l}$ of saliva, urine, semen and $100 \mathrm{mg}$ of feces dissolved in an isovolume of distilled water were deposed on an inert surface (glass), allowed to dry and put into contact with the moistened reactive tab of the strip of Combur $\underline{3}^{\text {Test }}{ }^{\circledR}$ E.

\subsection{Interfering Substances}

Several compounds, known to be potential interfering for the detection and the individualization of blood by the catalytic tests $[4,5,6]$, were chosen and classified according to the potential positive or negative interference and on the putative interference mechanism (Table 1) and tested.

Based on the potential positive or negative interfering effects of a wide category of heterogeneous substances different preparation and testing procedures were accomplished as described below and in 
Table 1.The preparation of the substances was carried out in order to simulate the presence of such substances at the crime scene based on reference [16].

\subsubsection{Positive interference evaluation}

To assess the potential positive interfering effect of several compounds (described in Table 1) for the detection and the individualization of blood by the Combur $\underline{3}$ Test ${ }^{\circledR}$ E several liquid and solid substances were investigated.

For liquid substances two different protocols were followed:

- $10 \mu \mathrm{l}$ of each substance undiluted and diluted in distilled water according to the dilution factors reported in Table 1 were deposed on paper and on glass; the obtained traces, once dried, were put into contact with the reactive tab of the strip of the Combur $\underline{3}$ Test $^{\circledR}$ E.

- $10 \mu \mathrm{l}$ of each solution were deposed directly on the reactive tab of the strip of the Combur ${ }^{3}$ Test ${ }^{\circledR}$ E. For solid substances the reactive tab of the Combur ${ }^{3}$ Test $^{\circledR} \mathrm{E}$ was directly put into contact with the compounds.

\subsubsection{Negative interference evaluation}

To assess the potential negative interfering effect of several compounds (described in Table 1) for the detection and the individualization of blood by the Combur $\underline{3}$ Test $^{\circledR}$ E $10 \mu$ l of each compound were mixed with $10 \mu \mathrm{l}$ of human blood (blood samples from individuals $1,2,3$ ), undiluted and diluted to $2 \cdot 10^{-1}, 10^{-1}, 10^{-2}, 10^{-3}, 10^{-4}, 10^{-5}$. Aliquots of $10 \mu \mathrm{l}$ of the obtained solutions were deposed on glass and tested with the Combur ${ }^{3}$ Test $^{\circledR}$ E. $10 \mu \mathrm{l}$ of human blood samples from individuals 1, 2, 3, without addition of any compound, were diluted as described, deposed on glass and tested. Such samples were used as positive control.

\subsection{Thermal inhibition test}

To investigate the impact of the peroxidase enzymes over the catalysis in the redox reaction of the Combur $\underline{3}^{\text {Test }}{ }^{\circledR}$ E, a thermal inactivation of such enzymes was carried out by boiling several positive interfering substances for different times. Particularly 13 different positive interference vegetable derivatives (listed in Table 1) were put into $1.5 \mathrm{ml}$ vials and immersed in boiling water at $100{ }^{\circ} \mathrm{C}$ for 5 , 10, 15 and 20 minutes. Also 3 blood samples were tested to verify that heating does not or slightly affect the peroxidase-like activity of the of the oxidized hem prosthetic group. At each time $10 \mu \mathrm{l}$ of each boiled substance were spotted on paper, let dry and put into contact with the reactive zone of the strip of the Combur ${ }^{3}$ Test ${ }^{\circledR}$ E. Additionally $10 \mu$ l of each unboiled substance were tested and compared with the corresponding boiled substance. 
Table 1. Positive and negative interfering chemical, environmental and evaluation.

\section{Interfering substances tested}

\section{Positive interfering substances tested}

A. Compounds that have peroxidase or peroxidase-like activity

Fruit and vegetables:

Pineapple (juice)

Red orange (juice)

Peach (juice)

Apple and banana (juice)

Tomato (sauce)

Tomato (pulp)

Potato (pulp)

Onion (pulp)

Apple (pulp)

Banana (pulp)

Carrot (pulp)

Plant substances

Grass (homogenized)

Flowers (homogenized)

Pine bark (fragment)

Beverages

Beer

Coffee (infusion)

Tea (infusion)

Chamomile (infusion)

Chemicals compounds containing metal ions acting as inorganic catalysts

$\mathrm{MgSO}_{4}(1.12 \mathrm{mg} / \mathrm{ml})$

$\mathrm{FeSO}_{4}(2.58 \mathrm{mg} / \mathrm{ml})$

$\mathrm{CuSO}_{4}(1.48 \mathrm{mg} / \mathrm{ml})$

$\mathrm{MnSO}_{4}(1.57 \mathrm{mg} / \mathrm{ml})$

$\mathrm{Fe}_{2} \mathrm{O}_{3}(1.48 \mathrm{mg} / \mathrm{ml})$

B. Chemicals compounds with high oxidant capacity

$K I(1.54 \mathrm{mg} / \mathrm{ml})$

$\mathrm{KMnO}_{4}(1.47 \mathrm{mg} / \mathrm{ml})$

$\mathrm{NaBO}_{3}(1.43 \mathrm{mg} / \mathrm{ml})$

Detergents

Delicate bleach: Wial $\left(\right.$ Todis $\left.^{\circledR}\right)$ 
Bleach: Oliclor ${ }^{\circledR}$

Bleach: Ace $^{\circledR}$

Chlorine active gel detergent: Donal Clor (Donal Professional ${ }^{\circledR}$ )

Neutral detergent:Terxil Super (Donal Professional ${ }^{\circledR}$ )

$50 \mathrm{mg} / \mathrm{ml}$ Multi-purpose Cleaner Degreaser: W5 ${ }^{\circledR}$

$100 \mathrm{mg} / \mathrm{ml}$ Multi-purpose Cleaner Degreaser: W5 ${ }^{\circledR}$

Whitening liquid: Pure White (Champagne Mousse ${ }^{\circledR}$ )

C. Complex chemical species that react with the test through an unknown mechanism

$\mathrm{Na}_{2} \mathrm{CO}_{3}(0.49 \mathrm{mg} / \mathrm{ml})$

Methyl Violet Base

$1.8 \mathrm{mg} / \mathrm{ml} \mathrm{K}$ EDTA

Ammunitions

Rusty Iron Fragment

Body Paint of some Cars

Dead insects on the windshields of some cars

Lipsticks GEMEY® (71 pastel macrè)

Leather Shoes

\section{$\underline{\text { Negative interfering substances tested }}$}

A. Compounds acting as detergents and oxidizing species (diluted 1:5)

Delicate bleach: Wial (Todis ${ }^{\circledR}$ )

Chlorine active gel detergent:Donal Clor (Donal Professional)

Neutral detergent: Terxil Super (Donal Professional ${ }^{\circledR}$ )

Whitening liquid: Pure White (Champagne Mousse ${ }^{\circledR}$ )

B. Compounds acting as antioxidants species

Ascorbic Acid ( $5 \mathrm{mg} / \mathrm{ml}$ )

Aspirin C (40 mg/ml acetylsalicylic acid, $24 \mathrm{mg} / \mathrm{ml}$ ascorbic acid)

Positive interfering substances used in the thermal inhibition test

Pineapple (juice)

Red orange (juice)

Peach (juice)

Apple and banana (juice)

Tomato (sauce)

Tomato (fragment)

Potato (fragment)

Onion (fragment)

Apple (fragment)

Banana (fragment)

Carrot (fragment)

Grass (homogenized)

Flowers (homogenized)

Human blood (sample 1,2,3) 


\subsection{Simulated forensic exhibits}

To simulate a real situation in which bloodstains were identified by the Combur ${ }^{3}$ Test $^{\circledR}$ E, $10 \mu l$ of human blood (sample 4) diluted to dilution factors 10-3, 10-4, 10-5, were deposed on different materials typically found at crime scene and let dry. In particular, the following sample types were used: two types of absorbent cotton materials, a kitchen knife, a screwdriver, a billhook, a rusty nail and two stoppers sink (a steel stopper sink and a brass stopper sink). The moistened reactive tab of the strip of the Combur ${ }^{3}$ Test ${ }^{\circledR}$ E was put into contact with the obtained evidence.

\subsection{Evaluation of putative interference of the Combur $\underline{3}$ Test ${ }^{\circledR}$ E chemicals with STRs DNA typing}

As other presumptive tests has proven to relevantly affect STRs typing $[4,17,18,19]$, we investigated whether or not the chemicals contained in the Combur $\underline{3}$ Test ${ }^{\circledR} \mathrm{E}$ reactive strips could affect the following DNA typing procedures, especially in LT DNA situations. To this purpose human bloodstains deposed on different surfaces at different dilution degrees and real evidences were put into contact with the test reactive pad chemicals and STRs genotyped.

\subsubsection{DNA Typing of human blood spots}

Aliquots of $10 \mu \mathrm{l}$ of human blood samples, undiluted and diluted as previously described, were put into contact with Combur $\underline{3}$ Test ${ }^{\circledR}$ E reagents and were processed as described below. Depending of the type of the surface of deposition of the stains, two different protocols, schematized in Fig. 2, were followed to evaluate the potential interfering effects of the Combur ${ }^{3}$ Test ${ }^{\circledR}$ E over the DNA typing procedures:

- bloodstains spotted on absorbent materials (including all of the dried caseworks samples) were entirely cut (usually about $5-6 \mathrm{~mm}^{2}$ of substrate) and put into a $1.5 \mathrm{ml}$ vial along with the tab of the Combur $\underline{3}$ Test ${ }^{\circledR}$ E reactive strip containing the chemicals; DNA was extracted from the blood sample, quantified and STRs genotyped;

- bloodstains spotted on non-absorbent surfaces were tested with Combur ${ }^{3}$ Test ${ }^{\circledR} \mathrm{E}$ and the reactive tab of the test was used as swab to collect the entire blood sample (10 $\mu$ l); DNA was extracted from the reactive tab used as swab to collect blood quantified and STRs genotyped. 


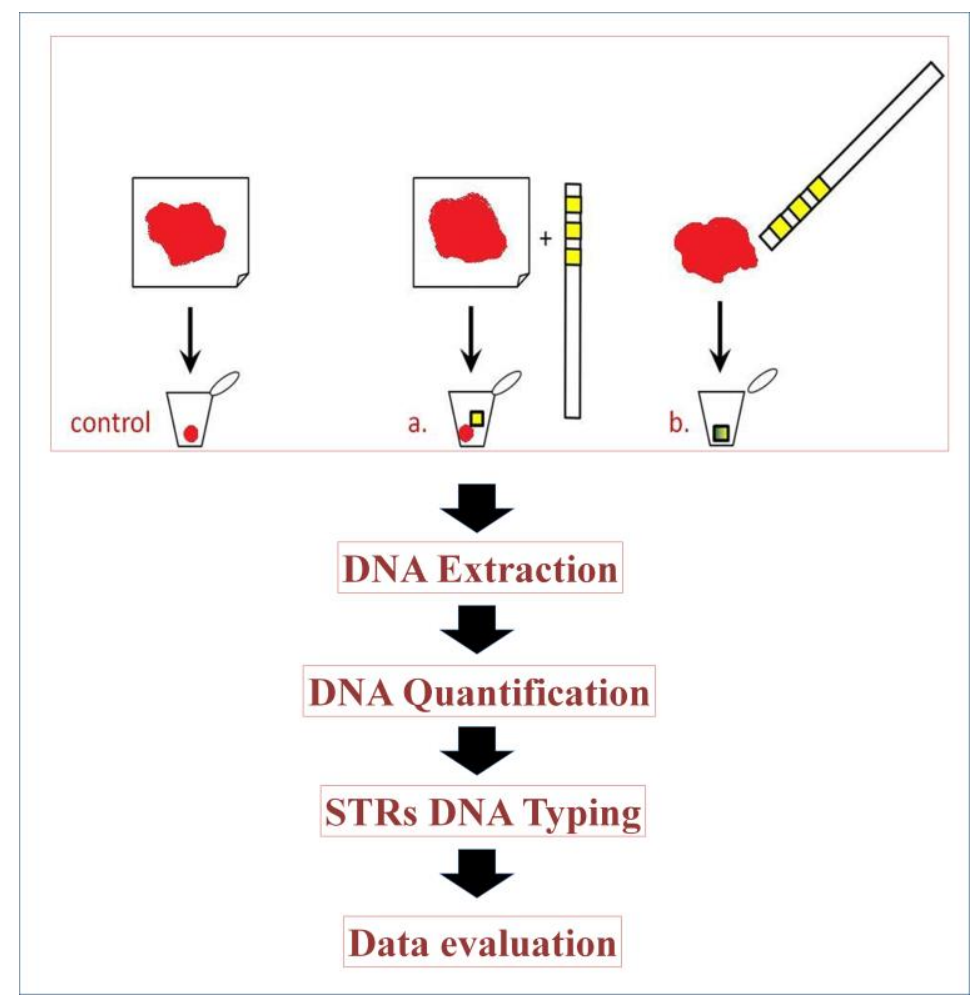

Each stain was processed three times. Bloodstains without Combur $\underline{3}$ Test $^{\circledR}$ E treatment were used as control samples. Both protocols were set to maximize the amount of the test chemicals in the solution undergoing the DNA extraction procedure, thus mimicking an extreme, unlikely, operational condition and allowing the evaluation of the worst possible detrimental effects of such chemicals on the DNA typing.

\subsubsection{DNA Typing of simulated and real bloodstain forensic evidences}

To simulate the operational protocol involving the actual use of the Combur ${ }^{3}$ Test $^{\circledR} \mathrm{E}$ and the following DNA typing simulated bloodstains evidences and real bloodstain evidences previously described were tested accordingly to the protocol previously suggested; depending on typology of the surface the bloodstain was recovered as much completely as possible by a swab (in case of non-absorbent surfaces) or portions of about $6 \mathrm{~mm}^{2}$ were cut from the surface (in case of absorbent surfaces). Blood samples were DNA extracted and STRs genotyped. Each stain was processed three times. Bloodstains without Combur $\underline{3}$ Test ${ }^{\circledR}$ E treatment were used as control samples. 


\subsection{DNA extraction, quantification and STRs genotyping}

DNA was extracted by the BioRobot EZ1 ${ }^{\circledR}$ Advanced XL Workstation following the bloodstains EZ1 ${ }^{\circledR}$ DNA Investigator Card protocol (Qiagen, Hilden, Germany), based on a silica covered magnetic particle technology, and resuspended in $40 \mu \mathrm{l}$ of TE buffer (10 mM Tris- $\mathrm{HCl}, \mathrm{pH}$ 8.0, $1 \mathrm{mM}$ EDTA) provided by the manufacturer according to the user's manual protocol. DNA extracts were quantified by Investigator ${ }^{\circledR}$ Quantiplex HYres Kit (Qiagen, Hilden, Germany) on the Rotor-Gene Q (Qiagen, Hilden, Germany), according to the user's manual protocol. The claimed LoD of the Investigator ${ }^{\circledR}$ Quantiplex HYres Kit was $4.9 \mathrm{pg} / \mu \mathrm{L}$ of human DNA reproducibly detectable across replicates.

STRs loci were amplified by the AmpFeSTR ${ }^{\circledR}$ NGM SElect ${ }^{\mathrm{TM}}$ PCR Amplification Kit (Life Technologies, Carlsbad, CA, USA) and PowerPlex ${ }^{\circledR}$ ESI 17 System (Promega Corporation, Madison, WI, USA) in a Veriti $^{\text {тм }}$ Thermal Cycler (Life Technologies, Carlsbad, CA, USA) according to the respective user's manuals protocols.

DNA fragments were separated and detected by capillary electrophoresis in an Applied Biosystems 3500xl Genetic Analyzer (Life Technologies, Carlsbad, CA, USA), and data were analyzed by Data Collection Software and GeneMapper ${ }^{\circledR}$ ID-X Software v. 1.4 (Life Technologies, Carlsbad, CA, USA). In order to evaluate a potential decrease in the recovered DNA from Combur $\underline{3}$ Test $^{\circledR}$ E treated bloodstains by using an extraction method based upon a paramagnetic beads technology $[17,18,19]$ quantification data were evaluated to estimate:

- if the DNA extraction yield was depressed leading to a reduction on the amount of extracted DNA available for multiplex- PCR of STRs loci;

- in case of depression, either if it could be due to the destruction on the DNA present in the bloodstain or if it could be caused by the inhibition of the DNA extraction process by the test chemicals.

Such evaluations were possible by looking at the Internal Control (IC) contained in Investigator ${ }^{\circledR}$ Quantiplex HYres system, which is synthetic DNA fragment co-amplified with each sample during quantification, thus providing information on interfering compounds in the DNA extract.

Because of the variability in the quantification process by the real-time PCR methods quantification result were divided based on the LoD of the test $4.9 \mathrm{pg} / \mu \mathrm{L}$ of human DNA into three categories: $\geq \mathrm{LoD}$; $<$ LoD; undetected. This approach was adopted to minimize the variability of absolute quantification results and avoid possible misleading of the actual significance of the results. 
283 Genetic profiles were quantitatively evaluated considering two parameters: the average height of 284 allele peaks and the percentage of successfully typed STRs alleles; both values were calculated over all 285 the STRs loci of the genetic profiles obtained from multiple analyses of all the samples in order to 286 guarantee the reliability of the results. The percentage of STRs loci was calculated considering the 287 number of successfully typed alleles from the same bloodstain in replicates over the expected full 288 number of alleles from the reference profile.

These parameters were calculated, according to several published recommendations $[6,20,21,22]$, 291 taking into account only STRs loci possessing alleles above a limit of detection (analytical threshold) of 292 50 RFU, a PHR > 60\% (only for STRs heterozygous loci), no relevant artifacts, confirmed over the replicates and fully concordant with the respective reference samples.

The average height of allele peaks was calculated to evaluate the putative effect of the chemicals of the test on the overall intensity of the allele peak signals all of the STRs loci in a genetic profile; the percentage of successfully typed STRs loci was calculated to investigate the putative effect on the recovery of STRs loci above the aforementioned acceptance cut-off values. Data were compared and 299 plotted.

\section{Results and Discussion}

302

\subsection{Detection of blood}

The ability of the Combur $\underline{3}$ Test $^{\circledR}$ E to detect blood was evaluated by depositing $10 \mu$ of fresh human blood samples at several dilutions on both absorbent and non-absorbent surfaces followed by testing (further details are reported in Table A1). The test was consistently able to detect blood to dilutions down to $10^{-4}$ for all surfaces. Blood deposited on non-absorbent surfaces (sheet metal painted and glass) at a dilution of $10^{-5}$ gave a still recognizable positive result indicating that blood samples containing at least $0.10-0.15 \mu \mathrm{g} / \mathrm{mL}$ of human hemoglobin can be still reliably detected by the

Positive and negative results were always correctly and reliably identified; moreover positive results could be also approximately distinguished, based on the intensity and the kinetics of the color change, in strong positive (intense dark blue-green color appeared almost immediately), which was observed for more concentrated bloodstains (dilution $<10^{-2}$ ), moderately positive (greenish color appeared usually within 10 seconds) which was observed for more diluted bloodstains $\left(10^{-2}<\right.$ dilution $\left.\leq 10^{-3}\right)$ and weak positive results (pale greenish to yellow color appeared usually within 20 seconds) which was observed for extremely diluted bloodstains (dilution $>10^{-3}$ ). This provides some semiquantitative 
indications of the quantity of blood present, although this would need to be very carefully interpreted when used operationally.

On the basis of these results the lower boundary of its ability to provide reliable detection of human blood is at least $0.10 \mu \mathrm{g} / \mathrm{mL}$ of human hemoglobin (blood diluted about $2.5 \times 10^{5}$ times). This is a detection threshold slightly below that reported for the commercially available Hemastix ${ }^{\circledR}$ test and, more generally, for the traditional protocol of TMB-based presumptive tests for blood $[3,4,5]$.

Since blood samples diluted more than $10^{3}$ times are practically invisible or poorly visible to the naked eye, especially when shed over dark surfaces, the high sensitivity of the test allows its use also to presumptively test the presence of latent questioned blood, in addition to the luminol test (which is not interfering with TMB-based tests) $[6,23]$ or in its substitution when the stain is scant and has to be preserved as much as possible.

\subsection{Specificity}

All non-human blood samples showed a strong positive result confirming that the test is not selective for human blood. All of the samples of bird feces resulted moderately positive when tested with the Combur $\underline{3}$ Test ${ }^{\circledR}$ E; such results were probably provoked by the presence of minute occult blood traces. All the human biological fluids tested (saliva, urine and semen) gave negative results when tested with the Combur ${ }^{3}$ Test ${ }^{\circledR}$ E, with the exception of two samples each from two different individuals, in one case saliva and in the other urine, which showed a weak positive result most likely due to the presence of an unnoticeable quantity of blood. Similarly to bird feces, and most probably due to the presence of minute occult blood traces, the majority of samples of human feces (about 80\%) from healthy donors resulted moderately positive when tested with the Combur $\underline{3}$ Test ${ }^{\circledR}$ E.

\subsection{Interfering substances and thermal inhibition test}

To examine the effect of potential interferences on the performance Combur ${ }^{3}$ Test ${ }^{\circledR}$ E a range of substances that may be present at crime scenes and could cause potential interference with the Combur3 Test ${ }^{\circledR}$ E were investigated. The potential interferents were divided into two categories; those likely to give a positive interference (Table 2) and those likely to cause a negative interference (Table 3). 
Table 2. Evaluation of potentially positive interfering chemical, environmental and household substances in the Combur ${ }^{3}$ Test ${ }^{\circledR}$ E commonly found at the crime scene.

\begin{tabular}{|c|c|c|c|c|c|c|c|}
\hline Positive interfering substances & \multicolumn{7}{|c|}{ Combur $\underline{3}$ Test ${ }^{\circledR}$ E results } \\
\hline & \multicolumn{7}{|c|}{ Substance Dilutions } \\
\hline D. Compounds that have peroxidase or peroxidase-like & 1 & $2 \cdot 10^{-1}$ & $10^{-1}$ & $10^{-2}$ & $10^{-3}$ & $10^{-4}$ & $\begin{array}{c}10- \\
5\end{array}$ \\
\hline $\begin{array}{l}\text { activity } \\
\text { Fruit and vegetables }\end{array}$ & & & & & & & \\
\hline Pineapple (juice) & +++ & ++ & + & - & - & - & / \\
\hline Red orange (juice) & +++ & ++ & + & - & - & - & / \\
\hline Peach (juice) & +++ & ++ & + & - & - & - & / \\
\hline Apple and banana (juice) & ++ & + & + & - & - & - & / \\
\hline Tomato (sauce) & ++ & + & - & - & - & - & / \\
\hline Tomato (pulp) & ++ & + & - & / & / & / & / \\
\hline Potato (pulp) & ++ & + & - & / & / & / & / \\
\hline Onion (pulp) & ++ & + & - & / & / & / & / \\
\hline Apple (pulp) & ++ & + & - & / & / & / & / \\
\hline Banana (pulp) & ++ & + & - & / & / & / & / \\
\hline Carrot (pulp) & ++ & + & - & / & / & / & / \\
\hline Plant substances & & & & & & & \\
\hline Grass (homogenized) & + & - & / & / & / & / & / \\
\hline Flowers (homogenized) & + & - & / & / & / & / & / \\
\hline Pine bark (fragment) & + & - & / & / & / & / & / \\
\hline Beverages & & & & & & & \\
\hline Beer & - & / & / & / & / & / & / \\
\hline Coffee (infusion) & - & / & / & / & / & / & / \\
\hline Tea (infusion) & - & / & / & / & / & l & / \\
\hline Chamomile (infusion) & - & / & / & / & / & / & / \\
\hline $\begin{array}{l}\text { Chemicals compounds containing metal ions acting } \\
\text { as inorganic catalysts }\end{array}$ & & & & & & & \\
\hline $\mathrm{MgSO}_{4}(1.12 \mathrm{mg} / \mathrm{ml})$ & - & / & / & / & / & / & / \\
\hline $\mathrm{FeSO}_{4}(2.58 \mathrm{mg} / \mathrm{ml})$ & ++ & + & - & / & / & / & / \\
\hline $\mathrm{CuSO}_{4}(1.48 \mathrm{mg} / \mathrm{ml})$ & ++ & + & - & / & / & / & / \\
\hline $\mathrm{MnSO}_{4}(1.57 \mathrm{mg} / \mathrm{ml})$ & - & / & / & / & / & / & / \\
\hline $\mathrm{Fe}_{2} \mathrm{O}_{3}(1.48 \mathrm{mg} / \mathrm{ml})$ & - & / & / & / & / & / & / \\
\hline E. Chemicals compounds with high oxidant capacity & & & & & & & \\
\hline$K I(1.54 \mathrm{mg} / \mathrm{ml})$ & - & / & / & / & / & / & / \\
\hline $\mathrm{KMnO}_{4}(1.47 \mathrm{mg} / \mathrm{ml})$ & ++ & + & - & / & / & / & / \\
\hline $\mathrm{NaBO}_{3}(1.43 \mathrm{mg} / \mathrm{ml})$ & ++ & + & - & / & / & / & / \\
\hline Detergents & & & & & & & \\
\hline Delicate bleach: Wial (Todis $\left.{ }^{\circledR}\right)$ & - & - & - & - & - & - & - \\
\hline Bleach: Oliclor ${ }^{\circledR}$ & - & + & + & - & - & - & - \\
\hline Bleach: Ace ${ }^{\circledR}$ & - & - & - & + & + & + & - \\
\hline Chlorine active gel detergent: Donal Clor (Donal & - & - & - & - & - & - & - \\
\hline
\end{tabular}




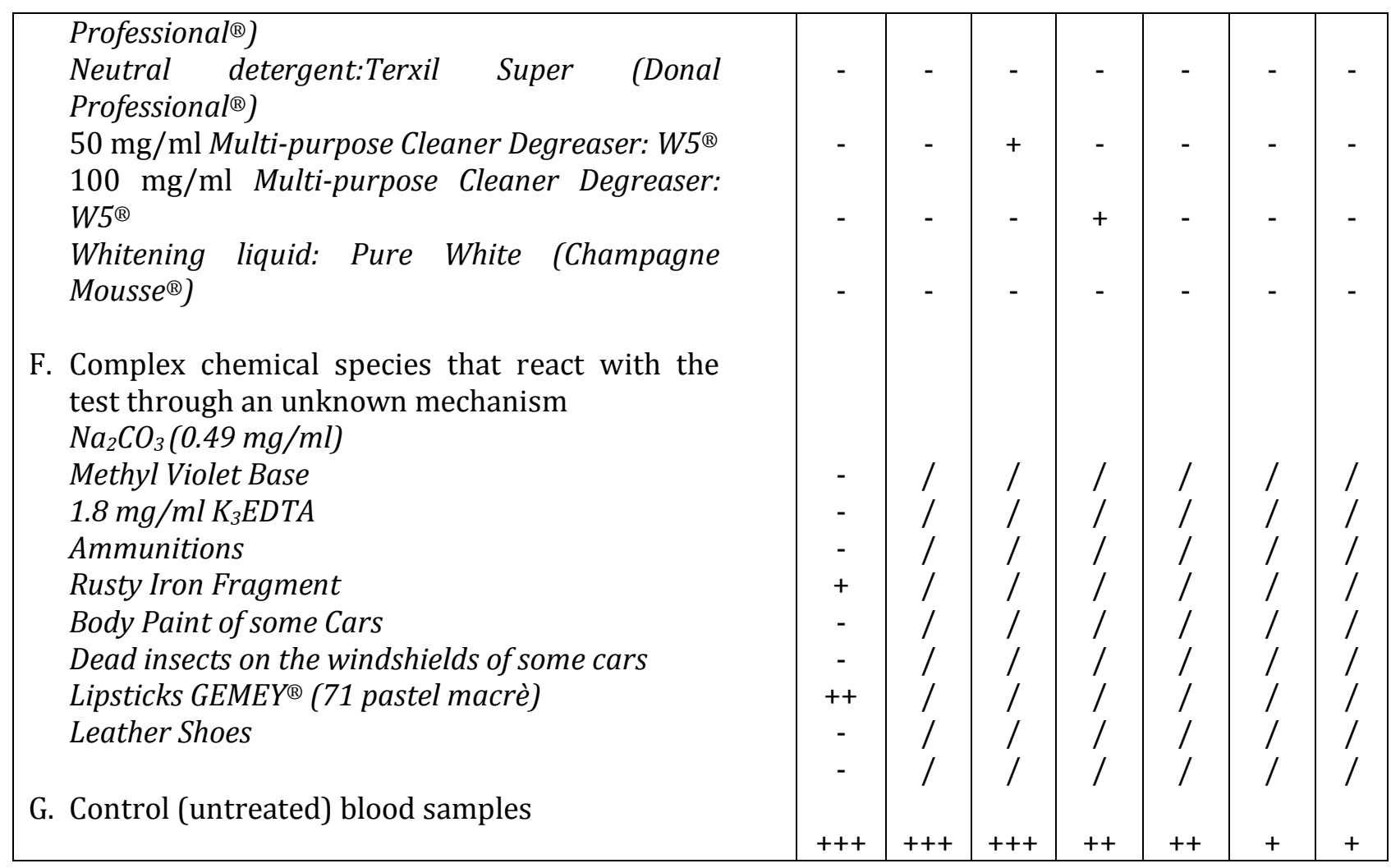

Notes:

+ low positive result; the contact of the reactive tab of the strip of the Combur 3 Test ${ }^{\circledR}$ E with the bloodstain showed a clearly visible color change from yellow to pale greenish.

++ moderate result; the contact of the reactive tab of the strip of the Combur 3

Test $^{\circledR} \mathrm{E}$ with the bloodstain showed a clearly visible color change from yellow to greenish.

- : $\quad$ negative result; the contact of the reactive tab of the strip of the Combur ${ }^{3}$ Test ${ }^{\circledR}$ to intense dark blue-green.

/ : $\quad$ Combur $\underline{3}$ Test ${ }^{\circledR}$ E not executed 
Table 3. Evaluation of potentially negative interfering chemical, environmental and household substances in the Combur ${ }^{3}$ Test ${ }^{\circledR}$ E commonly found at the crime scene.

\begin{tabular}{|c|c|c|c|c|c|c|c|}
\hline Negative interfering substances & \multicolumn{7}{|c|}{ Combur $\underline{3}$ Test ${ }^{\circledR}$ E results } \\
\hline \multirow{2}{*}{$\begin{array}{l}\text { C. Compounds acting as detergents and } \\
\text { oxidizing species (diluted } 1: 5 \text { ) }\end{array}$} & \multicolumn{7}{|c|}{ Human Blood Dilutions } \\
\hline & 1 & $2 \cdot 10^{-1}$ & $10^{-1}$ & $10^{-2}$ & $10^{-3}$ & $10^{-4}$ & $10^{-5}$ \\
\hline Delicate bleach: Wial (Todis $\left.{ }^{\circledR}\right)$ & +++ & +++ & ++ & ++ & + & + & - \\
\hline $\begin{array}{l}\text { Chlorine active gel detergent:Donal Clor } \\
\text { (Donal Professional) }\end{array}$ & +++ & +++ & ++ & ++ & + & + & - \\
\hline $\begin{array}{l}\text { Neutral detergent: Terxil Super (Donal } \\
\left.\text { Professional }{ }^{\circledR}\right)\end{array}$ & +++ & +++ & + & + & + & + & - \\
\hline $\begin{array}{l}\text { Whitening liquid: Pure White } \\
\text { (Champagne Mousse }{ }^{\circledR} \text { ) }\end{array}$ & +++ & ++ & + & + & + & + & - \\
\hline $\begin{array}{l}\text { D. Compounds acting as antioxidants } \\
\text { species }\end{array}$ & +++ & +++ & ++ & + & + & - & - \\
\hline $\begin{array}{l}\text { Ascorbic Acid }(5 \mathrm{mg} / \mathrm{ml}) \\
\text { Aspirin } C \text { ( } 40 \mathrm{mg} / \mathrm{ml} \text { acetylsalicylic acid, } \\
24 \mathrm{mg} / \mathrm{ml} \text { ascorbic acid) }\end{array}$ & +++ & +++ & ++ & + & + & - & - \\
\hline E. Control (untreated) blood samples & +++ & +++ & +++ & ++ & ++ & + & + \\
\hline
\end{tabular}

Note:

1. See Table 2 notes for results interpretation.

Fruit and vegetable materials are the most likely source of false positive results in this presumptive test for blood, most likely due to the enzymatic activity of peroxidases, as confirmed by the thermal inhibition test (Table 4). The application of heat deactivates the enzymes causing the positive interference. Most of the fruit and vegetable samples showing a positive interference with the Combur $\underline{3}$ Test ${ }^{\circledR} \mathrm{E}$, did not give a positive result after a thermal treatment of 15 minutes. The exception of grass that still maintained a residual interfering capacity against the test, perhaps because of the chlorophyll molecule which has a slight peroxidase-like activity [6]. 
Table 4. Thermal inhibition test to evaluate the positive interference in the in the material.

\begin{tabular}{|l|c|c|c|c|c|}
\hline \multirow{2}{*}{ Positive interfering substances } & \multicolumn{5}{|c|}{ Combur $\underline{3}$ Test ${ }^{\circledR}$ E results } \\
\hline \multirow{3}{*}{ Pineapple (juice) } & \multicolumn{5}{|c|}{ Time of thermal inactivation } \\
Red orange (juice) & \multicolumn{5}{|c|}{ (heating to 100 ${ }^{\circ}$ C) } \\
Peach (juice) & Unboiled & 5 min. & 10 min. & 15 min. & 20 min. \\
\cline { 2 - 6 } Apple and banana (juice) & ++ & ++ & + & + & - \\
Tomato (sauce) & ++ & ++ & + & - & - \\
Tomato (fragment) & ++ & + & - & - & - \\
Potato (fragment) & ++ & ++ & + & + & - \\
Onion (fragment) & ++ & ++ & - & - & - \\
Apple (fragment) & ++ & ++ & - & - & - \\
Banana (fragment) & ++ & - & - & - & - \\
Carrot (fragment) & ++ & + & - & - & - \\
Grass (homogenized) & ++ & ++ & - & - & - \\
Flowers (homogenized) & ++ & - & - & - & - \\
Human blood (sample 1) & ++ & ++ & + & - & - \\
Human blood (sample 2) & ++ & ++ & ++ & ++ & + \\
Human blood (sample 3) & ++ & - & - & - & - \\
& ++ & ++ & ++ & ++ & ++ \\
Control blood samples & ++ & ++ & ++ & ++ & ++ \\
& ++ & ++ & ++ & ++ & ++ \\
& & & + & & \\
& ++ & +++ & +++ & +++ & ++ \\
\hline
\end{tabular}

Notes:

See Table 2 notes for results interpretation.

It should be noticed that, especially with oxidizing species (particularly bleaching), the colorimetric reaction of the test was quite different from that observed in presence of blood concerning the colour intensity and/or time of color appearance: such compounds mimicking blood with the test and providing positive results either quenched the blue-green color intensity or altered (slowing down or speeding up) the colour development, or both.

Substances that may give a negative interference, either due to their antioxidant activity or some other complex reaction with the test reagents, were examined for their effect on the successful detection of blood at a series of dilutions. The results, summarized in Table 3, hinted that all of the compounds showed some effect, however it did not prevent detection of blood down to blood dilutions of $10^{-4}$ with the exception of a slight effect from ascorbic acid (pure and contained in Aspirin ${ }^{\circledR} \mathrm{C}$ ) which provided 
with a significant reduction in the test signal till to a dilution of $10^{-3}$. Interference effects evaluation and thermal inactivation assays (Table 4) confirmed also that hematin molecule and its peroxidaselike activity are chemically stable, also when mixed with detergents. These data were supported by the thermal inactivation tests conducted on blood samples. Such samples, even in denaturing conditions, always gave positive results with the test, suggesting that the hematin molecule is thermally stable and confirming that it is the catalytic species in the redox reaction underlying the test.

\subsection{Robustness}

The robustness of the Combur ${ }^{3}$ Test $^{\circledR}$ E was evaluated by testing human blood samples that had been aged, heated or had been subjected to the addition of chemicals. No significant effect was observed on the successful performance of the test concerning the temperature effects and the age of the samples. Bloodstains mixed with detergents and oxidizing compounds described in Table 3 always yielded low $(+)$ to moderate $(++)$ positive results; the presence of oxidizing and, particularly, detergents provoked a decrease in the test visible band

\subsection{Precision and accuracy}

Concordance between the outcomes of repeated analyses of fresh human blood samples carried out with the Combur $\underline{3}^{2}$ Test ${ }^{\circledR} \mathrm{E}$ in the same operating conditions or varying the operating conditions (precision) was always $100 \%$ indicating that the test results are fully repeatable and reproducible. Analogously, the concordance between results obtained by Combur ${ }^{3}$ Test ${ }^{\circledR} \mathrm{E}$ in the replicated analysis of the same fresh human blood samples and by a confirmative immunochromatographic test employing monoclonal antibodies against human hemoglobin was always 100\% indicating the ability of the Combur $\underline{3}$ Test $^{\circledR}$ E to fully individualize actual blood samples.

4.6 Comparative analysis of the analytical performance of the Combur ${ }^{3}$ Test $^{\circledR} E$ and the most used presumptive tests for blood individualization

Comparative analysis results about the analytical performances of the Combur $\underline{3}$ Test $^{\circledR}$ E respect to other presumptive tests for blood detection (the Hemastix ${ }^{\circledR}$ test, the phenolphthalein test and the leucomalachite-green test) are reported in Table A2.

Concerning the ease of forensic use of the tests, the Hemastix ${ }^{\circledR}$ test and the Combur ${ }^{3}$ Test $^{\circledR}$ E were the most user-friendly compared to the phenolphthalein test and the leucomalachite-green test, both in term of time necessary to accomplish them (almost immediately) and in term of complexity of the execution procedure since only two steps (hydration of the tests and contact with the questioned sample) were needed to accomplish the tests. On the contrary, especially due to operational procedure 
and sensitivity, the phenolphthalein test and the leucomalachite-green test appeared as less performing that both the the Hemastix ${ }^{\circledR}$ test and the Combur ${ }^{3}$ Test $^{\circledR}{ }^{\circledR}$.

While the Hemastix ${ }^{\circledR}$ test performed comparably in many respects to the Combur ${ }^{3} \mathrm{Test}^{\circledR} \mathrm{E}$ it was noticed that the sensitivity of Combur $\underline{3}$ Test ${ }^{\circledR}$ E was slightly better and that the reactive zone of the strip of the Hemastix ${ }^{\circledR}$ test often broke into small pieces when it was put vigorously into contact with the putative blood, especially when the test is used over rough surfaces. In most cases, particularly when the bloodstain was deposed on absorbent surfaces, the chemical compounds contained in the reactive tab of the Hemastix ${ }^{\circledR}$ test passed onto the bloodstain and the color change appeared directly over the evidence rather than on the reactive pad. In comparison the Combur ${ }^{3}$ Test ${ }^{\circledR}$ E reagent strip dues not suffers from such issues due to its construction with the nylon mesh laminate which, covering and protecting the reactive surfaces.

\subsection{Putative interference of the Combur ${ }^{3}$ Test ${ }^{\circledR}$ E chemicals with STRs DNA typing}

Possible negative interference of the Combur $\underline{3}$ Test ${ }^{\circledR}$ E chemical species with DNA typing was investigated by testing diluted bloodstains spotted on different surfaces, simulated bloodstain evidences and real casework bloodstains evidences. Undiluted and diluted bloodstain spots were managed by two protocols (Fig. 2). These protocols were chosen to maximize the contact among the chemicals of the Combur ${ }^{3}$ Test ${ }^{\circledR}$ E and any DNA thus creating a particularly adverse condition for subsequent DNA typing. They are not intended to be the process recommended for forensic practice, rather a "worst-case" scenario. The simulated and real bloodstains were put into contact with the reactive tab according to the suggested forensic protocol, thus mimicking a real test employment. Both DNA quantification and STRs DNA typing data were taken into account to investigate such effects on the STRs DNA profiling.

\subsubsection{DNA Quantification}

DNA quantification results revealed a decrease in DNA recovered by bloodstains exposed to the Combur $\underline{3}$ Test ${ }^{\circledR}$ E at every dilution factor, a significant difference between Combur $\underline{3}$ Test $^{\circledR}$ E exposed and unexposed blood samples was achieved at dilutions equal to and greater than $10^{-3}$ : the mean of the replicated quantifications of $10^{-3}$ and through $10^{-4}$ to $10^{-6}$ diluted bloodstains, come into contact with the Combur $\underline{3}$ Test ${ }^{\circledR}$ E, were considerably lower than the LoD and/or undetected (further details are reported in Table A3). IC coamplified with all DNA samples had always Cycle threshold (Ct) values equal to or less than 30 also in samples exposed to the Combur $\underline{3}$ Test ${ }^{\circledR}$ E chemicals, indicating no relevant inhibition in the experimental conditions used. In untreated bloodstains quantification result above the LoD were always gained till to $10^{-3}$ dilutions. Quantification results achieved from bloodstains coextracted with the Combur ${ }^{3} \operatorname{Tes}^{\circledR}{ }^{\circledR}$ tab were comparable in both the protocols followed. 
Such results are consistent with previous findings $[4,17,18,19]$, that the chemical species contained in the Combur $\underline{3}$ Test ${ }^{\circledR}$ E do show some negative interfering effects on the DNA extraction process conducted by a silica covered magnetic particle technology, the effect being the more relevant, the higher the dilution degree. Since no detectable increases were noticed on the Ct values for the IC, the most probable explanation to such interference was the decrease in the DNA extraction yield provoked by chemical byproducts of the oxidized TMB molecules binding to the silica paramagnetic beads in the extraction environment thus competing with the DNA fragments for the binding $[17,19]$.

Diluted bloodstains on simulated evidences for all the dilutions $\left(10^{-3}, 10^{-4}, 10^{-5}\right)$ as well as real caseworks bloodstains exposed to the Combur ${ }^{3}$ Test $^{\circledR}$ E direct protocol averagely yielded the same results as the respective unexposed bloodstains (further details are reported in Table A3) corroborating the clue that in the routinely suggested forensic use of the test DNA quantity and quality are not impaired.

\subsubsection{STRs DNA Typing}

Accordingly to DNA quantification data human bloodstains deposed on simulated evidences at dilutions of $10^{-3}, 10^{-4}$ and $10^{-5}$ to simulate LT DNA conditions, exposed to Combur Test $^{\circledR}$ E as in a normal use, did not suffer of any detrimental effect as insignificant differences in both STRs allele peak intensities and percentage of successfully typed STRs alleles appeared with respect to unexposed control bloodstains (Fig. 3). Analogously, also bloodstains from real caseworks (even 37 years old), were unaffected by the Combur ${ }^{3}$ Test ${ }^{\circledR}$ E testing. For bloodstains diluted through $10^{-5}$ to $10^{-6}$, genetic STRs alleles above the established acceptance limits were found neither for treated, nor for untreated bloodstains. An overall reduction in the DNA extraction yield for both diluted and undiluted bloodstains only if heavily come into contact with the test compounds (which is a quite unusual occurrence); this phenomenon was most likely due to the chemical interactions between ionic forms of oxidized TMB and the silica-covered magnetic beads $\left(\mathrm{SiO}_{2}-\mathrm{Fe}_{3} \mathrm{O}_{4}\right)$ in the presence of one or more chemical compound imbedded in the chemical strip which prevents DNA from binding to the silica magnetic beads. Such decrease in the extracted DNA unavoidably negatively reflected on following DNA typing affecting all the diluted bloodstains but provoking practical consequences only on medium-high diluted samples (blood samples diluted to $\geq 10^{3}$ times). In the normal suggested forensic use of the test (simulated and real forensic bloodstains), where usually a mixing of the test chemicals with blood does not happen, a substantial reduction in DNA quantity was unnoticed and, consequently, STRs DNA typing was not jeopardized by the Combur $\underline{3}$ Test ${ }^{\circledR}$ E, even when LT DNA bloodstains were tested. The effects of a reduction of template DNA could impact the ability to gain acceptable DNA profile only when the bloodstain was extremely diluted (at least hundreds of times), while previous 
512 works conducted by first generation multiplex PCR had demonstrated a much higher impact of the test 513 chemicals on DNA typing (even at minor dilution factors).

514 Therefore the Combur ${ }^{3}$ Test ${ }^{\circledR}$ E chemical components may, in theory, negatively prevent DNA typing 515 procedures but, in operational terms, such negative interference may have significant negative pitfalls 516 on bloodstains only if two conditions are contemporarily met: when blood is (1) considerably 517 embedded with the chemical compounds (including TMB), which is an quite unrealistic occurrence, 518 and (2) when it is diluted $\geq 10^{3}$ times, which is a typical LT DNA condition.

519 In usual forensic caseworks, and even in LT DNA situations, at the crime scene and in the laboratory, 520 the proper use of the Combur $\underline{3}$ Test $^{\circledR} \mathrm{E}$ by both the direct and the indirect protocols with bloodstains 521 diluted to or more than $10^{3}$ folds does not practically impair the last generation DNA typing 522 procedures. Anyway, a special awareness should be used with LT DNA situations where even the 523 presence of minute amount of chemical may compromise the ability to achieve useful DNA profiles. 524 When it is deemed to be dealing with such special situations a reduction in time and/or surface of 525 contact between the test reactive tab and the stain or an indirect testing approach with Combur ${ }^{3}$ Test $^{\circledR}$ 526 E may be preferably suggested. 
A

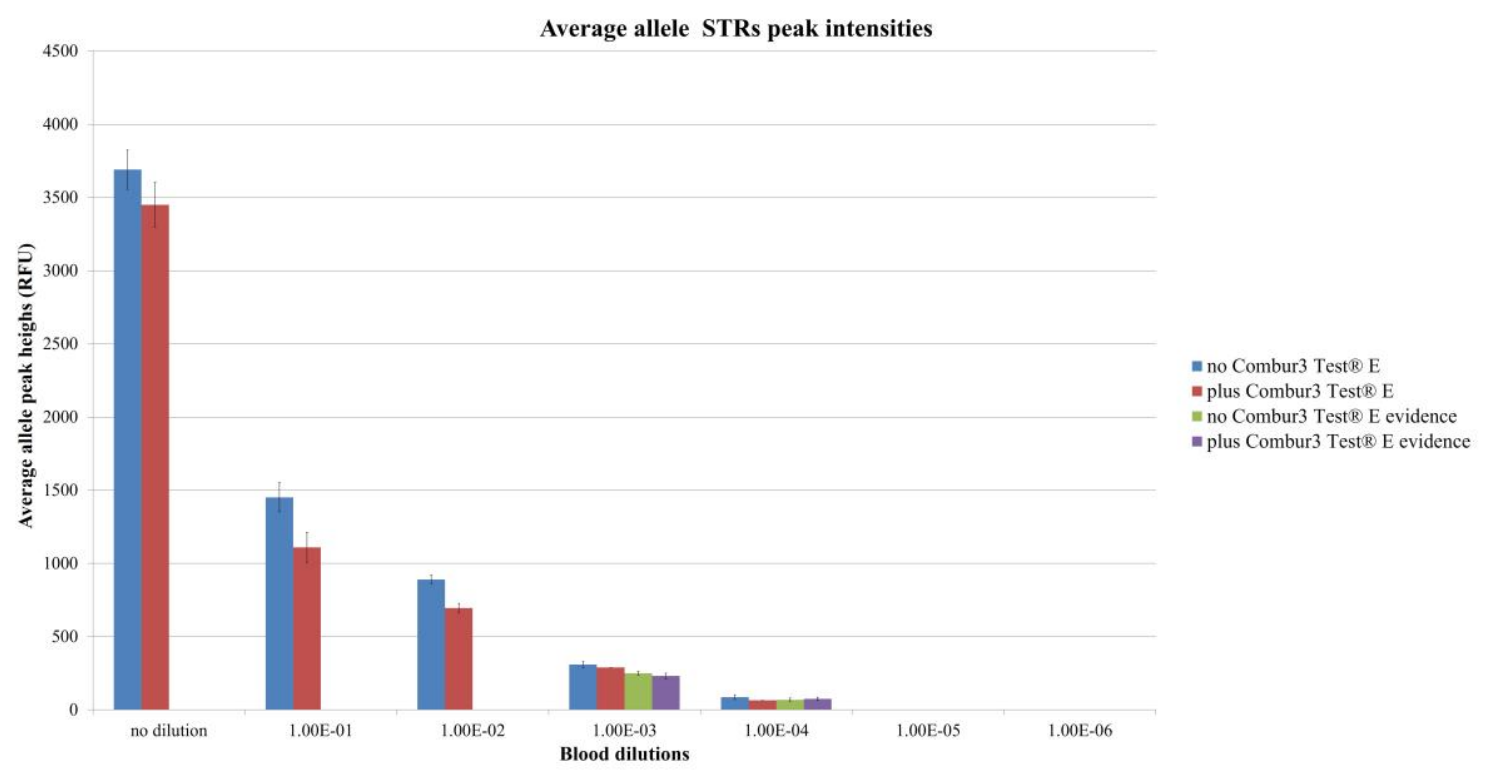

B

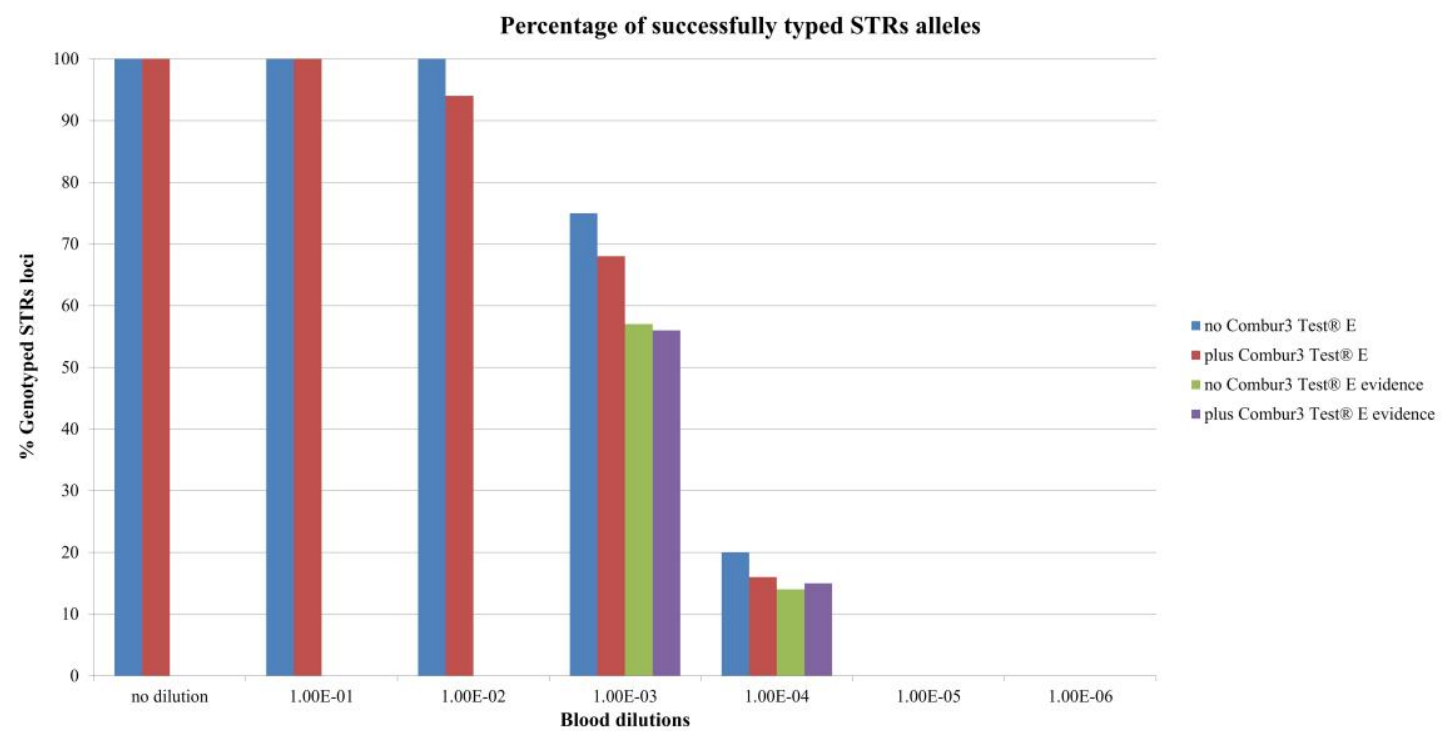

528 Fig. 3. Average height of the peaks of the electropherograms (A) and percentage of successfully typed 529 STRs alleles (B) from the STRs DNA typing of several fresh human blood samples (undiluted and 530 diluted down to $10^{-6}$ ), spotted on different surfaces, of bloodstains on simulated forensic evidences 531 (only diluted to $10^{-3}, 10^{-4}, 10^{-5}$ ), both with and without the Combur $\underline{3}$ Test ${ }^{\circledR}$ E treatment. Data obtained from the analysis of the stains in absence or in presence of the reactive tab of the Combur ${ }^{3}$ Test ${ }^{\circledR} \mathrm{E}$ were represented in blue and in red in case of spotted bloodstains and in green and in violet in case of bloodstains on simulated evidences; values of heights are expressed in relative fluorescence units 535 (RFU) and derived from the average peak heights of all the genetic loci analyzed for each of the dilution factors related to bloodstains examined (analytical threshold $=50 \mathrm{RFU}$ ). 
540 In conclusion, this forensic validation work proved that the Combur $\underline{3}$ Test $^{\circledR}$ E shows analytical 541 performances fitted-to-purpose for the presumptive identification of latent or evident bloodstains at 542 the crime scene and in the laboratory. The format of the test and our suggested protocols of use 543 (detailed in Table A4), make the test better performing and much easier to use than other analogous 544 presumptive tests in every operational condition. Provided the test is appropriately used, it is usually 545 compatible with STRs DNA typing protocols without relevant detrimental effects, even on LT DNA 546 bloodstains. The Combur $\underline{3}$ Test ${ }^{\circledR}$ E gives reliable outcomes, which, if correctly managed by experienced 547 personnel according to the suggested guidelines, is a valuable tool for both investigative and 548 evidentiary purposes.

\section{Acknowledgments}

551 None.

552

\section{References}

554

[1] Li R. Forensic Biology: Identification and Analysis of Biological Evidence. Boca Raton, FL, USA,

[2] Johnston E., Ames C.E., Dagnall K.E., Foster J., Daniel B.E. Comparison of presumptive blood test kits including hexagon OBTI, J Forensic Sci. 53(3):687-9 (2008).

[3] Gaensslen RE. Sourcebook in forensic serology, immunology and biochemistry. Washington, D.C.:

[4] Tobe SS, Watson N, Daéid NN. Evaluation of six presumptive tests for blood, their specificity, sensitivity, and effect on high molecular-weight DNA. J Forensic Sci. 2007 Jan;52(1):102-9.

[5] D.D. Garner, K.M. Cano, R.S. Peimer, T.E. Yeshion, J Forensic Sci. 21(4) (1976) 816-821. An evaluation of tetramethylbenzidine as a presumptive test for blood.

[8] International Organization for Standardization/International Electrotechnical Commission (ISO/IEC). ISO/IEC 17025:2005 General Requirements for the Competence of Testing and Calibration Laboratories. ISO/IEC, Geneva, Switzerland. 
Validation and Related Topics: Second edition https://www.eurachem.org/index.php/publications/guides/mv.

[10] IUPAC (2014). Compendium of Chemical Terminology (Gold Book), Release 2.3.3, available at: http://goldbook.iupac.org/.

[11] Thompson M., Stephen L.R.E., Wood R. (2002). Harmonized Guidelines for Single Laboratory validation of methods of analysis - IUPAC Technical Report. Pure Appl. Chem., 74 (5):835-855.

[12] ICH (2005). Harmonised Tripartite Guideline. Validation of Analytical Procedures: Text and Methodology Q2(R1), available at: http://www.ich.org/products/guidelines/quality/article/quality-guidelines.html.

[13] A.Greenfield, M.M. Sloan, and R. P. Spaulding. Identification of Blood and Body Fluids. Identification and Characterization of Blood and Bloodstains. In: Forensic Science: An Introduction to Scientific and Investigative Techniques. Fourth edition. Edited by S. H. James, J. J. Nordby, and S. Bell. Boca Raton, Flo, USA CRC Press, 2014.

[14] Combur ${ }^{3}$ Test ${ }^{\circledR}$ E technical specification sheet v. 3.0 (2014), Roche Diagnostics, Basel, Switzerland.

[15] Cox M. (1991). A study of the sensitivity and specificity of four presumptive tests for blood. J Forensic Sci. 1991 Sep;36(5):1503-11.

[16] Bluestar False Positives Study Report (2008). Bluestar ${ }^{\circledR}$ Forensic, Monte Carlo, Monaco), available online at: http://www.bluestar-forensic.com/pdf/en/false positives 2008 study.pdf.

[17] Poon H, Elliott J, Modler J, Frégeau C. The use of Hemastix and the subsequent lack of DNA recovery using the Promega DNA IQ system. J Forensic Sci. 2009 Nov;54(6):1278-86.

[18] Petersen D, Kaplan M. The use of Hemastix ${ }^{\circledR}$ severely reduces DNA recovery using the BioRobot ${ }^{\circledR}$ EZ1. J Forensic Sci. 2011 May;56(3):733-5.

[19] Frégeau CJ, De Moors A. Competition for DNA binding sites using Promega DNA IQ ${ }^{\text {TM }}$ paramagnetic beads. Forensic Sci Int Genet. 2012 Sep;6(5):511-22.

[20] Budowle B, Eisenberg AJ, van Daal A., "Validity of low copy number typing and applications to forensic science", Croat Med J. 50(3):207-17 (2009).

[21] Buckleton J, Validation issues around DNA typing of low level DNA. Forensic Sci Int Genet. 3(4):255-60 (2009).

[22] SWGDAM Interpretation Guidelines for Autosomal STR Typing by Forensic DNA Testing Laboratories (Federal Bureau of Investigations, USA, 2010).

[23] Webb JL, Creamer JI, Quickenden TI. A comparison of the presumptive luminol test for blood 
with four non-chemiluminescent forensic techniques. Luminescence. 2006 Jul-Aug;21(4):214606 20. 